\title{
Os Conselhos de Psicologia, a formação e o exercício profissional
}

$\mathrm{O}$ artigo examina as funçōes das entidades formadoras (faculdades, universidades) e fiscalizadoras/orientadoras (CRPs, CFP) de profissionais na área de Psicologia, argumentando em favor de uma atuação não dissociada das mesmas, na medida em que formação e exercício profissional se apresentam, em diversos contextos, de modo articulado. A parceria é defendida como necessária para garantir tanto uma formação adequada quanto o próprio desenvolvimento da ciência e da profissão.

\section{Adriano Holanda}

CRP 01 - Brasilla - Mestre em psicologia, clinica pela UNB e doutorando em psicologia na PUC/Campinas

Este trabalho visa expor algumas reflexōes sobre as funçōes dos Conselhos Regionais e Federal de Psicologia e a formação dos psicólogos. Sabemos que existe uma fronteira relativamente extensa que separa o que é do campo da Formação - e se associa às Entidades Formadoras (Faculdades e Universidades) e que se constitui num campo denominado de "Docente"- e o que é do âmbito da Fiscalização e da Orientação - como funções primárias dos Conselhos de Psicologia e, portanto, no terreno do "Exercício Profissional".

A reflexão que se segue se propõe a reavaliar estas questões, assinalando que não há significativa distínção entre o que é exercício profissional e o que é formação profissional. Dentro da atual perspectiva da ciência, de atuar na interdisciplinaridade, não se julga cabível delimitar campos estreitos de ação de entidades que, direta ou indiretamente, utilizam-se de prerrogativas semeIhantes. Numa perspectiva dialética, o que se percebe é um continuum entre a Formação e o Exercício Profissional.

Os Conselhos de Psicologia e as Instituiçōes Formadoras devem estabelecer critérios conjuntos de ação, sendo que muitas das delimitaçōes do campo docente podem, e devem ser encarados (jurídica e formalmente) como campos de interface, adentrando no terreno do Exercício Profissional e, portanto, da esfera de atuação dos Conselhos, como é o caso da Supervisão de Estágio em Formação de Psicólogos, por exemplo.

Outra reflexāo importante diz respeito a um redimensionamento das "atribuiçōes" dos Conselhos, segundo a legislação vigente, que aponta para a orientação, a fiscalização e a disciplina do exercício profissional. Neste âmbito, faz-se necessário rediscutir a sentido destas atribulçōes à luz da atualidade e à luz da interface de atuação profissional.

\section{A Funcionalidade dos Conselhos de Psicologla}

Os Conselhos de Psicologia constituem-se na máxima representação dos profissionais da área. Assim designados pela legislação em vigor, que atribui aos Conselhos de Psicologia a manutenção e estruturação da profissão através de algumas funçōes especialmente designadas.

De acordo com a Lei No.5.766, de 20/ 12/71, que "cria o Conselho Federal e os Conselhos Regionais de Psicologia", temos que são atributos e prerrogativas dos Conselhos:

"...orlentar, disciplinar e fiscalizar ö exercício da profissão de Psicólogo e zelar pela flel observâncla dos princíplos de ética e disciplina da classe". 1

No Decreto No.79.822, de 17/06/77, que "regulamenta a Lei No.5.766", as finalidades do Conselho Federal de Psicologla são de:

"...orientar, supervisionar e disciplinar o exercíclo da profissão de Psicólogo, em todo o territórío nacional". ${ }^{2}$
'Capítulo ( (Dos Fins), Art.01, Lef
No.5.766.
${ }^{2}$ Art.03, Decreto No.79.822/77. 


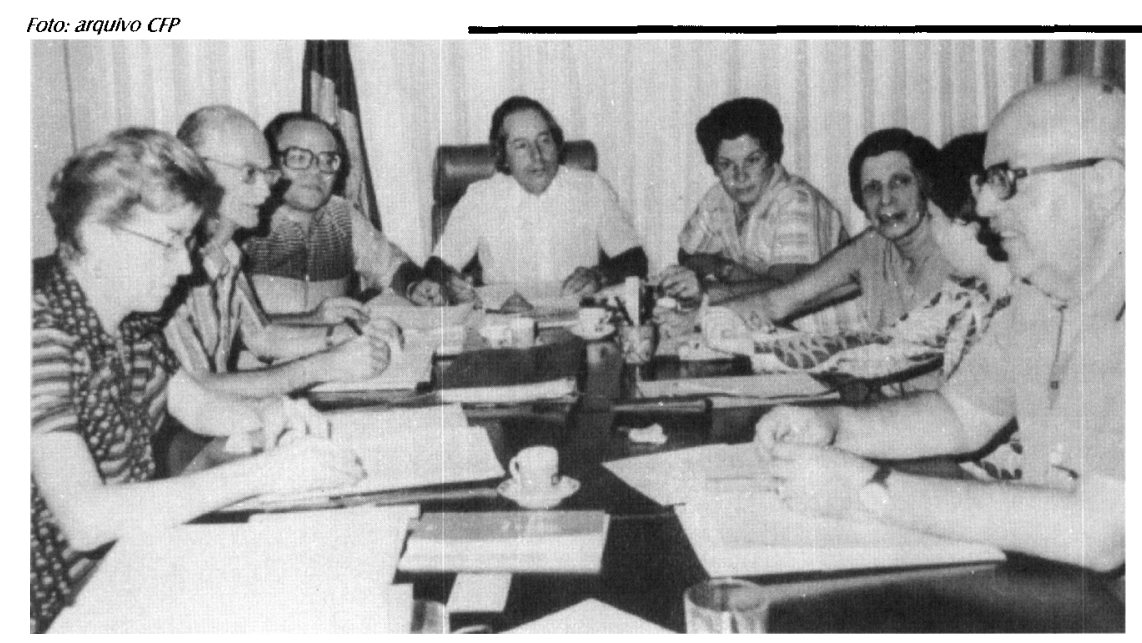

Segundo Plenário do Conselho Federal de Psicologia - 1972

Na elaboração das atribuições do Conselho Federal - como órgão máximo
${ }^{3}$ Art.06 da Lei No.5.766.

"Art.06, Alínea "g", Lei No.5.766. Grifos nossos. de legitimação e legislação da categoria profissional - convém destacarmos algumas alíneas, referentes à sua atuação enquanto autarquia representativa da classe dos psicólogos, no que tange às suas competências, ou seja, "compete" ao Conselho Federal:

b) orientar, disciplinar e fiscalizar o exercício da Profissão de Psicólogo; c) expedir as resoluçōes necessárias ao cumprimento das leis em vigor e das que venham modificar as atribuiçōes e competência dos profissionais de Psicologia;

d) definir, nos termos legais, o limite de competência do exercício profissional, conforme os cursos realizados ou provas de especialização prestadas em Escolas ou Instituiçōes Profissionais reconhecidos". ${ }^{3}$

Chama-nos a atenção esta última alínea, quando se estabelece, na própria legislação, a necessidade de se ter uma interação ativa entre os ConseIhos de classe e as Instituiçōes Formadoras ou demais congregacōes profissionais. Este parece-nos ser o ponto crucial, principalmente, pelo fato de não se ter esta determinação clara do campo do exercício profissional.

Quando a legislaçāo estabelece que cabe ao Conselho Federal "servir de órgão consultivo em matéria de Psicologia" ${ }^{4}$, está determinando que esta autarquia possui poderes e direitos estabelecidos para traçar parâmetros dentro de um campo científico por demais vasto e complexo, e por que não assinalar, produto e criador de interfaces intelectuais significativas.

Numa rápida reflexão, encontramos uma forte dissonância, quando pensamos que o campo ou a "matéria" da Psicologia, enquanto estrutura de pensamento e formulação científica não podem ser privativas de uma determinada instância, a nāo ser que assim se determine a priori pela comunidade de psicólogos, o que se constituiria num estabelecimento com fortes componentes corporativistas (em que pese a necessidade de sermos, por vezes, corporativistas), mas essencialmente de cunho dicotômico, onde se encara a ciência como parcialidade e não como uma inserção global na historicidade do pensamento.

É claro que o fato de ser um órgāo "consultivo" atenua estas dificuldades, mas permanece o questionamento, na medida em que não se determina de antemão qual o terreno de atuaçāo dos Conselhos, visto haver ainda hoje uma forte celeuma em torno do conceito de Exercício Profissional.

Ao se falar de "exercício profissional", temos de refletir sobre a dimensāo global de seu conceito: sua estrutura e sua dinâmica.

Como afirmam Kast e Rosenberg (1970), "o conceito de profissão envolve: (a) a existência de um corpo sistemático de conhecimento que requer lento processo de formacão e treinamento, envolvendo tanto aspectos intelectuais como atividades práticas; (b) um grau de autoridade conferida pelos clientes em função do conhecimento técnico especializado; (c) um amplo reconhecimento social como base para o exercício da autoridade; (d) um código de ética que regula as relações entre pares e entre o profissional e os seus clientes; e (e) uma cultura profissional que é mantida pelas organizacões".(Apud Bastos \& Achcar, 1994: 246)

O mais importante, contudo, a ser re- 
levado, é que os parâmetros definidores de uma profissão são flexíveis e, portanto, passíveis da ação da transformação pelos anos e pelo desenvolvimento das idélas. Assim é que a definição de "exercício profissional" também deve acompanhar o fluxo da evolução do pensamento e, principalmente, a evolução da inserção social e profissional da Psicologia.

\section{A Formação do Psícólogo}

"...a psicologia não é um saber, mas é um plural. $O$ que se organiza nesse campo não é a unidade e o homogêneo, mas sim, a diversidade e o heterogêneo, a diferença". (Mendonça Filho, 1993: 68)

É sabido que uma das principais críticas feitas à formação do profissional de Psicologia reside no fato de se privilegiar uma formação individualista e egocentrista, onde o profissional da Psicologia permanece fechado, em sua maioria, aos problemas referentes à sua classe e à sociedade como um todo.

Neste sentido, os Conselhos devem ter um papel ativo por serem instâncias privilegiadas, e por congregarem a dimensão macro da classe profissional. Uma aproximação dos ConseIhos junto às Universidades, com o intuito de estabelecer parcerias em termos de aproveltamento de espaços para pesquisas e encaminhamentos acerca do mercado de trabalho, inserção social do psicólogo, elaboração de planos e metas de desenvolvimento de recursos para a colocação do profissional junto à comunidade e, principalmente, 0 desencadeamento de um trabalho de esclarecimento à população em geral e ao público profissional sobre o real papel do psicólogo parecem ser de fundamental importância.

Quem determina o que o aluno deve saber? A Universidade, a comunidade científica, o Ministério da Educa- ção ou o Conselho da categoria? A questão da formação do psicólogo já vem passando por diversos questionamentos nos últimos anos, culminando em trabalhos, pesquisas e discussões que envolvem, principalmente, a reforma curricular (no sentido de adaptar o currículo mínimo aos progressos da ciência psicológica), acompanhamento dos cursos de graduação (no âmbito da avaliação dos cursos existentes e preocupação com os novos cursos), e outros temas. ${ }^{5}$

o Campo de atuação do psicólogo, ou seja, o terreno do exercício profissional continua mal definido, devido em parte, a uma complexidade epistemológica que diversificou e amplificou os campos de atuação do profissional da Psicologia. Estamos num momento onde é imprescindível o diálogo inter e transdisciplinar com outras categorias, visto a Psicologia estar ocupando espaços que, historicamente, sempre foram de outras áreas. A interface do exercício profissional do psicólogo com, por exemplo, administradores, médicos, assistentes sociais, pedagogos, advogados e outros, vem crescendo sobremaneira nos últimos anos, como pode ser facilmente comprovado pela literatura do Conselho Federal de Psicologia.

Um dos principais problemas da definição do "exercício profissional" do psicólogo deve-se, em grande parte, ao que assinala Bastos:

"O modelo hegemônico de atuação psicológica, forjado ao longo dos anos, especialmente após a regulamentação da profissão e conseqüente estabelecimento de padrōes para a formação dos novos profissionais". (Bastos, 1988: 163)

O que se observa em nivel de desenvolvimento de idéias psicológicas é uma ampliação das concepçōes teórico-práticas, no sentido de encarar a Psicologia como uma subjetividade inter-relacionada, ou como assinala a filosofia fenomenológica, como uma intersubjetividade, o que implica na inserção do indivíduo na sociedade e nas relações culturais, como agente e promotor de mudanças.
${ }^{5}$ No âmbito deste debate, $a$ Revista Psicologia, Ciêncla e Profissâo é pródiga em oferecer excelente material para discussão e espaco para divulgação de idélas relativas ao tema - crucial para a categoria. 
3. O Papel dos Conselhos na Formação Profissional

Podemos iniciar a nossa discussão sobre o papel efetivo dos Conselhos de Psicologia no âmbito da Formação Profissional a partir da análise de quatro vertentes principais de sua atuação, a saber:

a) vertente política;

b) vertente de regulamentação;

c) vertente de orientação e fiscalizaçào;

d) vertente de formação e aperfeiçoamento do psicólogo.

No que tange à vertente política, a discussão se volta para questionamentos sobre a relação entre Psicologia e política, ou mesmo sobre qual o papel político da Psicologia. As discussōes sobre este tema invariavelmente esbarram em concepções psicossociais que perdem de vista "a especificidade do psicológico" (Araújo, 1996). Na realidade, isto não abarca o real papel social do psicólogo, como um profissional promotor da saúde do indivíduo e do bem-estar da comunidade. É preciso que o psicólogo assuma seu papel como transformador da realidade e, para isto, é fundamental que a Formação seja engajada com um compromisso ético.

Os Conselhos, enquanto autarquias responsáveis pelo zelo da ética da profissão, devem também se engajar na tarefa de promover a discussão e o desenvolvimento de uma consciência ética da profissão. Neste sentido, estará cumprindo com parte de sua função social.

O que entendemos como a vertente política do Conselho diz respeito à mobilização e organização da categoria em torno de questōes que sejam do seu interesse imediato e da sociedade em geral. Este aspecto é de extrema importância dado o fato de nossa formação não privilegiar esta inserção ética do profissional, estimu- lando um modelo de atuação individualista. Além disso, é imprescindível a criação de parcerias junto aos órgãos superiores do Poder Legislativo no sentido de implementação de lutas pela categoria e pelo social, além de uma aproximação com as instâncias governamentais referentes às áreas de Educação, Saúde e Trabalho, para que se possa efetivar programas de ação social devidamente embasados e respaldados pela categoria e pela ciência psicológica.

Convém ainda assinalar que qualquer ação na realidade social - seja de forma direta ou indireta - é, essencialmente, um ato político. Não estamos com isto confundindo Sindicatos com Conselhos, mas tão somente pontuando para o fato que os Conselhos não podem e não devem se eximir de sua responsabilidade política, enquanto órgãos legislativos, organizativos e congregadores.

Nisto introduzimos a segunda vertente, a vertente de regulamentação, que se refere ao papel de legislador sobre o exercício da profissão e de realizador do cumprimento desta legislação. Neste âmbito, creio que o papel do Conselho se confunde com a terceira vertente, no sentido de ser um órgão muito mais orientador do que propriamente legislador (em que pese a necessidade de se fazer cumprir a lei e o código de ética), na medida em que a inserção da imagem da Psicologia entre os psicólogos e, principalmente, na comunidade em geral, é de desconhecimento de suas atribuiçōes. Ainda outro comentário sobre este ponto: regulamentar visa primordialmente a organizaçāo; atributo essencial para o estabelecimento de um quadro profissional claro e destacado.

A terceira instância, a vertente de orientação e fiscalização, diz respeito às principais prerrogativas dos Conselhos. $\mathrm{Na}$ medida em que estas duas atividades - orientação e fiscalização - são inndissociáveis, deve-se privilegiar o sen- 
tido da orientação por ser de caráter profilático e informativo, contribuindo para um melhor esclarecimento do quadro de referência da Psicologia, visto que, conforme assinalado anteriormente, é sabido que a categoria profissional dos psicólogos não domina adequadamente as informaçōes acerca de seus órgãos legisladores.

Nesta discussão, nos interessa a quarta vertente, a vertente da formação $e$ aperfeiçamento do psicólogo, que deve ser privilegiada. Entendemos que, primeiramente, nāo se pode considerar como categorias estanques, de um lado a Formação e de outro o Exercício Profissional.

Se os Conselhos não se comprometerem com um acompanhamento da Formaçāo do futuro psicólogo, eles estarão se eximindo de uma responsabilidade ética e mantendo o status de pensamento dicotomizado, arcaico e contraproducente, tendo em vista que se deve trabalhar no sentido de uma profilaxia de dificuldades e não no âmbito do "conserto" ou de um papel "policialesco".

A idéia reside no fato que o comprometimento dos Conselhos não devem ser apoiados apenas a partir do momento em que o estudante sai do âmbito acadêmico e adentra o terreno profissional. Pensar desta forma é não refletir na continuidade do processo de formação, nem considerar a relação Formação/Profissão, que é o objetivo do próprio processo. Em outras palavras, a atualidade não mais permite que se considere, em nome das interrelaçōes, papéis fechados de atuação, ou seja, o que é da Universidade e o que é dos Conselhos, por exemplo.

Esta vertente, portanto, encara a dimensão da formação num sentido mais amplo, que abrange desde o acompanhamento do futuro profissional da Psicologia, até o acompanhamento da abertura e/ou fechamento de cursos de graduação nesta área. O II Congresso Nacional da Psicologia, realizado em 7
Belo Horizonte, de 28 de agosto a $1^{\circ}$ de setembro de 1996, apresentou uma unânime opinião dos Conselhos Regionais contra a abertura de novos cursos de Psicologia no país (enquanto não se tiver uma política de fiscalização da formação atual) e ratificou a necessidade de se realizar uma profunda avaliação dos cursos em vigor no Brasil, bem como a aproximação dos Conselhos junto aos órgãos competentes do Ministério da Educação no sentido de um acompanhamento continuado das atividades de ensino e formação de profissionais na área de Psicologia. Todos estes direcionamentos estavam de acordo com o I Congresso Nacional da categoria.

Se observarmos agora as específicas atribuiçōes de um Conselho de Psicologia, podemos verificar que, a título de exemplificação, segundo o Regimento Interno do CRP-01, cabe à Câmara de Formação Profissional, agir sobre os "assuntos relacionados com a graduaçāo e pós-graduação do psicólogo, a universidade, os órgãos e entidades que cuidam do ensino da Psicologia, bem como todos aqueles correlatos que lhe sejam atribuídos pelo Plenário".

De acordo com os encaminhamentos do Congresso Nacional Constituinte da Psicologia, as açōes do Conselho deveriam se pautar em alguns direciohamentos:

a) Um compromisso social da Psicologia, no âmbito da transformação da realidade nacional;

b) Um compromisso científico do psicólogo, com vistas à produção e disseminação do conhecimento;

c) Um compromisso com a interdisciplinaridade, com relação à integração e articulação dos valores e conhecimentos da Psicologia com as demais áreas;

d) Um compromisso com a qualificação dos responsáveis pela formação de novos profissionais;

e) o entendimento de que a formação do psicólogo deve ser básica. 
consistente e abrangente;

f) Um compromisso com uma formação que envolva um posicionamento ético e político, inserindo o profissional nas discussões sociais, no âmbito da organização da categoria e de uma postura de cidadania;

g) A idéia de que o processo de formação deve ser o de construção do conhecimento e de atitude científica, aqui entendida a partir de uma ampliação do próprio conceito de ciência; h) A ênfase numa formação generalista, que contemple a interdisciplinaridade, as demandas sociais, as relaçōes sociais e a diversidade da atuação profissional.

Com isto, os encaminhamentos políticos e de ação abrangem parcerias dos Conselhos com as Universidades na promoção de eventos e discussões sobre estas questōes de inserção social e política da Psicologia, campos de atuaçāo, abertura de novos mercados, distinção das diversas áreas de conhecimento, estágios e outros temas de relevância para a categoria.

Embora seja da alçada da Universidade determinar quem vai definir o procedimento de transmissão e formação de conhecimento, qual o modelo desta transmissão, etc, creio que uma parceria junto aos Conselhos só tem a acrescentar e aprimorar o trabalho da formaçāo profissional.

Duas dimensōes da formação profissional devem ser contempladas: em primeiro lugar, o espaço tradicional da formaçāo do psicólogo, cuja competência é atribuída à Academia, ou seja, às Instituições Formadoras, sejam estas Universidades ou Faculdades isoladas. Em segundo lugar, deve-se atentar para a chamada "pós-graduação", cuja diversidade e conceito são por demais amplos.

Uma "pós-graduaçāo" pode significar desde um curso "lato sensu" ou "strictu sensu", destinados em geral, ao aperfeiçoamento do profissional com vistas à prática específica a que se pro- pōe, até um Mestrado ou Doutorado, que têm como função primária a formação de docentes e pesquisadores. Em geral, estas atividades são reguladas por determinações do Ministério da Educação e, portanto, contam com acompanhamento da própria comunidade no sentido de validação de suas atjvidades.

\section{Carneiro (1993) assinala que:}

"Enquanto o lato sensu visa aprimorar a formação profissional, o stricto sensu visa formar o docente/pesquisador e desenvolver a produção do conhecimento na respectiva área".

Neste âmbito, entende-se de uma outra forma a questão da transmissão de conhecimentos específicos da Psicologia. Na dimensão extremamente vasta dos chamados "cursos de pós-graduação", destacamos aqueles que não se inserem num coritexto acadêmico, como os realizados por profissionais liberais ou por instituiçōes jurídicas desvinculadas da docência clássica.

Entende-se com isto que, fora do âmbito acadêmico, as atividades relativas aos cursos intitulados de "formação", "aperfeiçoamento", "treinamento" adentram o terreno do exercício profissional visto se proporem, invariavelmente, a habilitar para a própria ação profissional. Assim é que consideramos como do âmbito da orientação e da fiscalização dos Conselhos estes cursos, tendo em vista que:

1) É exercício da profissāo quando se propõem a veicular métodos e técnicas psicológicas (privativas do profissional) e não exercício de docência;

2) Adentram no terreno do estágio profissionalizante;

3) Se propõem a treinar habilidades, visando o exercício profissional do futuro psicólogo.

Segundo o Novo Dicionário da Língua Portuguesa (Ferreira, 1994), a "Formação" diz respeito a: 
1. Ato, efeito ou modo de formar.

2. Constituição, caráter.

3. Maneira por que se constitui uma mentalidade, um caráter ou um conhecimento profissional.

Entende-se com isto que a prática da "Formação" (ou Treinamento ou Especialização) realizada por profissional de Psicologia como pessoa física ou jurídica, que se proponha a transmitir ou treinar habilidades em Métodos e Técnicas Psicológicas, é encarado como Exercício Profissional e, portanto, como da alçada do Conselho de Psicologia.

Entende-se que o Exercício Profissional é função do psicólogo, conforme previsto na Lei No.4.119/62 e no Decreto No.53.464/64 em determinadas áreas. $\mathrm{Na}$ Consolidação das Resoluções do Conselho Federal de Psicologia (No.004/86), temos no seu Título IV (Do Exercício Profissional) o disposto a seguir:

“Art.49 - O psicólogo é pessoalmente responsável pelas atividades profissionais que exercer.

Art.50 - Sem prejuizo do caráter privativo da atividade profissional, o psicólogo poderá delegar funçōes a estagiário, como forma de treinamento.

Parágrafo 01 - A concessão de estágio deverá ocorrer somente em situação em que fique caracterizada a natureza didática de atividade a ser realizada pelo estagiário e sob condiçōes em que seja efetivamente possível supervisionar o trabalho do mesmo, respeitado o disposto na Legislação sobre o estágio curricular ou, quando couber, estágio extra-curricular previsto em Lel.

Parágrafo 02 - O psicólogo responsável obriga-se a verificar pessoalmente a capacitação técnica de seu estagiário, supervisionando-o e sendo o responsável direto pela aplicação adequada dos métodọs e técnicas psicológicas e pelo respeito à ética profissional.

Parágrafo 03 - Para os efeitos dispostos neste artigo, considera-se estagiário o estudante do ciclo profissional, de curso oficialmente reconhecido de graduação de psicólogo, regularmente ma09 triculado, cursando disciplinas profissionalizantes que envolvam atividades práticas e que atendam à legislaçāo sobre o estágio curricular ou extra-curricular". (Conselho Federal de Psicologia, 1995).

Portanto, é exercício profissional, a prática ou a transmissão da prática que venha a ser considerada como privativa do Psicólogo. Sobre este assunto temos a regulamentação oficial contida na Lei No.4.119/62 (que estabelece o que é prerrogativa do psicólogo) e no seu Decreto No.53.464/64 (que regulamenta a Lei 4.119) que dispõem:

\section{"São funçōes do psícólogo:}

1) Utilizar métodos e técnicas psicológicas com o objetivo de:

a) diagnóstico psicológico;

b) orientaçāo e seleção profissional;

c) orientação psicopedagógica;

d) solução de problemas de ajustamento..."

Se há consenso que estas práticas acima citadas constituem-se em prerrogativas básicas do profissional psicólogo, parece-nos lógico que a transmissão das mesmas também seja prerrogativa do psicólogo.

A idéia básica é de salvaguardar os estudantes de Psicologia no sentido de estarem posicionados em tarefas que Ihes sejam adequadas, além dos próprios profissionais. Mas o mais importante ainda é salvaguardar o usuário da Psicologia, para que ele tenha serviços de qualidade, e não apenas uma mão-de-obra em treinamento inadequado.

Uma das constatações mais gritantes, que se observa em nível de distorções no campo da Formação extra-acadêmica e do estágio supervisionado, é que muitas vezes o estudante, em nome de uma suposta "oportunidade de vivenciar a prática psicológica" é colocado, sem nenhum apoio e sem nenhuma competência teórico-prática, na qualidade de "mão-de-obra bara- 
ta", para realizar "serviços simples", como (pasmem!), aplicação e avaliação de testes psicológicos ou mesmo atendimento de uma clientela dificil e que demanda serviço especializado, como em hospitais, clínicas ou ainda consultórios, escolas e empresas.

O que mais surpreende é a consideraçāo que alguns colegas profissionais têm da sua própria área. Por exemplo: ao colocar que "qualquer um pode aplicar ou avaliar" um teste tal qual o PMK (comum em serviços psicotécnicos para carteira de habilitação), o profissional está desvalorizando o instrumento que ele mesmo usa e, muitas vezes, é sua maior fonte de trabaIho.

Esta discussão envolve, seguramente, uma visão dos cursos de graduação em Psicologia e a qualidade da formação que é dada nestas instituições. Porém, não podemos coadunar com uma prática comum em nossa profissão, que consiste em desvalorizar nosso próprio instrumental (que levou décadas para ser reconhecido e ainda luta para tal), nossa base epistemológica e nossa profissāo como um todo, a partir de profissionais que não demonstram compromisso ético com a categoria. Valorizar a Psicologia enquanto ciência e profissão, é valorizá-la como um todo, discutindo, questionando, mas antes de tudo, respeitando seus fundamentos.

Por estes motivos é que consideramos o seguinte:

1) Quando no tocante ao Estágio Supervisionado em Psicologia, constituise, tanto para o estagiário quanto para o supervisor de estágio, exercício da profissão de psicólogo ${ }^{6}$ (segundo a Lei No. 6.494 e o Decreto No. 87.497, de 18 de agosto de 1982, que regulamenta a Lei No. 6.494). Segundo o citado Decreto (Art. 20.), "Considera-se estágio curricular, para os efeitos deste Decreto, as atividades de aprendizagem social, profissional $e$ cultural, proporcionadas ao estudan- te pela participacão em situaçōes reais de vida e trabalho de seu melo..."

2) Constitui atribuição do Conselho Regional de Psicologia (consoante a Lei No. 5.766, que cria o Conselho Federal e os Conselhos Regionais de Psicologia e dá outras providências) orientar, aperfeiçoar, disciplinar e fiscalizar o exercício da profissão de psicólogo em sua área de competência, bem como, zelar pela fiel observância do Código de Ética Profissional, impondo sanções pela sua violação (Art. 09, alíneas " $b$ " e " ${ }^{\prime \prime}$ ), zelar pela dignidade e independência da profissão de Psicólogo.

3) Segundo a Lei No. 4.119 (que dispõe sobre os cursos de formação em Psicologia e regulamenta a profissão de Psicólogo), no capítulo referente aos direitos conferidos aos diplomados (Capítulo III), observa-se que (Art. 13), ao portador do diploma de Psicólogo é conferido o direito de ensinar Psicologia nos vários cursos de que trata esta lei, observadas as exigências legais específicas, e a exercer a profissão de Psicólogo.

4) Observa-se, entretanto, que segundo a Lei No. 4.119 (supra citada), para o exercício profissional de psicólogo é necessário ser portador de diploma de graduação em Psicologia, o qual deve ser regístrado no órgão competente do MEC (Lei No. 4.119, Capítulo III, Art. 10 e, Decreto No. 53.464, que regulamenta a Lei No. 4.119, Art. 03) e, ainda, é necessário possuir inscriçāo profissional no Conselho Regional de Psicologia da respectiva região de atuação (segundo Decreto No. 79.822, Art. 01, que regulamenta a Lei No. 5.766).

5) Acrescente-se ainda que, segundo o mesmo Decreto No. 53.464, Art. 04, sāo funçōes do psicólogo, além das supracitadas anteriormente, as seguintes: ensinar as cadeiras ou disciplinas de Psicologia nos vários níveis de ensino. observadas as demais exigências da legislação em vigor; e, supervisionar profissionais e alunos em trabalhos teóri-
Grifos nossos. Costa Jr \& Holanda, 1996. 
cos e práticos de Psicologia.

6) Considerando a Resolução CFP No. 004/86, que institui a Consolidação das Resoluçōes do Conselho Federal de Psicologia e conceitua todos os termos utilizados no Art. 13 (Parágrafo 01 da Lei No. 4.119), no que se refere às técnicas e métodos psicológicos, eliminando quaisquer dúvidas ou eventuais interpretações (divergentes) acerca da definiçāo e do entendimento de tais técnicas e métodos psicológicos, considera-se impossível conceber um Curso de "Formação" ou "Treinamento" em qualquer área da Psicologia, (incluindo objetivos gerais e específicos, atividades desenvolvidas, procedimentos e critérios de avaliação) sem utilizar o emprego das técnicas e métodos psicológicos (privativos do psicólogo) citados no Art. 13, da Lei No. 4.119.

7) Os Conselhos de Psicologia, considerando suas atribuições de orientador, disciplinador e fiscalizador do exercício da profissāo de psicólogo, têm o dever de questionar a prática e a transmissāo da prática da Psicologia nos mais diversos niveis.

8) A título de ilustração de nossa argumentação, convém lembrar que o Conselho Regional de Psicologia, 8a. Regiāo (PR), em parecer da Assessoria Jurídica, datado de 17 de fevereiro de 1993, sobre a necessidade de inscrição de Professores de Psicologia nos Conselhos Regionais de Psicologia, conclui que "não há qualquer dúvida, até por ter usado o legislador o mesmo termo - função - existente na Lei. No. 4.199, que ao ser regulamentado este diploma legal, quis significar o regulamento, que ensinar psicologia é uma funçāo psicológica", e propōe a obrigatoriedade do professor de Psicologia estar inscrito no Regional de sua área de Jurisdição. O citado Parecer observa, ainda, considerando que uma das funções do Psicólogo é supervisionar profissionais e alunos em trabalhos teóricos e práticos de Psicologia (conforme já explicitado no item. 07 desta ar- gumentação), "que aqueles que irão formar novos profissionais terāo de ter $o$ domínio e o conhecimento das técnicas e métodos próprios da ciência que irāo transmitir. Isto não poderia ser de outra forma, se impondo como dever social". Desta forma, ressalta o parecer, "teremos profissionais aptos a aplicar as funções psicológicas".

9) $\mathrm{Na}$ intenção de dar um direcionamento a esta questão, apresentamos tese $^{8}$ no II Congresso Regional da Psicologia sobre o tema. Esta tese propunha alguns encaminhamentos específicos, dentre os quais a elaboração de uma Resolução normatizadora. Com base nesta argumentação o Conselho Regional de Psicologia (1a Região), criou critérios de organização e normatização destes cursos através da Resolução No.005/96 que "Cría $o$ Cadastro de Cursos de Formação, Treinamento, Especialização e/ou Aperfeicoamento em Matéría de Psicologia e Estabelece Critérios de Regulamentacão para os citados Cursos, de caráter privado".

Diante disto é que consideramos da alçada dos Conselhos de Psicologia o acompanhamento das atividades que envolvam a transmissão da prática profissional privativa do Psicólogo (Métodos e Técnicas Psicológicas), envolvendo desde os chamados "Cursos de Formação, Treinamento, Aperfeiçoamento ou Especialização" na área de Psicologia, seja a partir do trabalho de profissionais liberais (pessoas físicas), seja através de pessoas jurídicas (instituiçōes, clínicas, institutos, núcleos, centros de estudos ou outros); até os cursos que se ocupam de técnicas psicológicas (em especial os que lidam com testes projetivos, de personalidade, etc).

Repensar a inserçāo social da Psicologia, implica também repensar a colocação da dimensão do profissional no seio da formação. Senão vejamos, como aponta Carneiro:

"Como ensinar e pesquisar nestas áreas [da Psicologia] sem ser profissio- 
nal? Como criticar e produzir o conhecimento em Psicologia Clínica sem ser clínico? Como fazê-lo fora da Universidade, fora dos cursos de Mestrado e Doutorado?". (Carneiro, 1993: 105)

Dentro da amplitude da discussāo sobre a Formação Profissional, verificamos que os estudos (Duran, 1994) envolvidos neste tema relevam aspectos os mais variados, tais como: grades curriculares, estágios acadêmicos ${ }^{9}$, dicotomias entre formação teórica e técnica ou entre formação de generalistas ou especialistas, análise de currículos específicos, diretrizes para a formação, etc. Todos os estudos concordam com uma idéia: a necessidade de se rever a questāo da formação do psicólogo.

A principal vertente na qual os ConseIhos devem trabalhar é no sentido de integração entre a prática profissional, a formação do psicólogo e a pesquisa (seja ela acadêmica ou não). Para isto é importante observarmos alguns elementos:

“Um ponto de partida para integrar a contribuição de cientistas, profissionais e educadores parece residir na crescente consciência acerca da complexidade dos fenômenos psicológicos, da sua multideterminação e da possibilidade de múltiplos níveis de descrição e intervenção. Tal consciência demanda, ao contrário do isolamento, uma postura de parceria entre todos". (Francisco \& Bastos, 1992: 220)

Uma parceria envolve um empenho mútuo na direção de uma formação adequada para o futuro psicólogo. Acredito que o fundamento primordial para que possamos vislumbrar uma formação globalizante seja a superação do pensamento dicotômico vigente em nossa cultura, onde se determinam espaços específicos de acão da pesquisa, da docência e do "exercício profissional", sem que se encarem estas três instâncias num todo organizado, indissociável e interrelacionado.
A ação dos Conselhos deve ser no sentido de atuar na complexidade, na globalidade da atuação da classe. Para isto, é de extrema importância que os Conselhos, as Instituições Formadoras e, principalmente, os profissionais desvinculados destas duas instâncias possam estabelecer um trabalho conjunto e progressivo para o desenvolvimento da profissão.

O profissional deve ser estimulado a ser um agente de mudança, e não apenas um reprodutor do conhecimento científico e técnico. Para tanto, é necessário que se amplie o conceito de ciência, superando o paradigma positivista e reinserindo profissional "expert" (Francisco \& Bastos, 1992) no papel de produtor e elaborador de teorias e conhecimentos.

Além disto tudo, os Conselhos não podem ficar à parte das lutas sociais da classe e, por isto, é fundamental que se tenha uma inserção ética da profissão, que implica num compromisso com o aprimoramento do profissional - seja este liberal ou docente, com o acompanhamento dos cursos de graduação, bem como empenho no sentido de haver uma melhor remuneração do profissional de ensino e de geração de meIhores condiçōes de trabalho para a formação profissional.

Uma idéia que pode ser efetivada através de uma ação conjunta Conselhos/Agências Formadoras, é de um acompanha nento continuado do processo de forma cão do Psicólogo a partir do momento em que este adentra no seio acadêmico até sua insercão no mercado de trabalho - que se dá sob duas vertentes: a do estágio supervisionado, enquanto uma "prática profissional concedida" (Costa Jr. \& Holanda, 1996) e do exercício autonômico da profissão.

Em suma, acredito que os Conselhos devem estar atentos para a integração dialética entre estudante, docente e profissional, bem como para a integração entre ciência, técnica e arte ou conhecimento, pesquisa e aplicação, para que se possa desenvolver a Psicologia em todas as suas vertentes.

\footnotetext{
${ }^{9}$ Sobre o assunto, reportamonos a artigo de Costa Jr \& Holan. da, 1996.

${ }^{8} \mathrm{~A}$ tese foi apresentada pelos entāo Conselheiros do CRP-OI Aderson Cosla Jr e Adriano Holanda.
} 
Araújo, M.F.(1996). "Reflexões sobre o Papel Social e Político do Profissional de Psicologia", referência incompleta.

Bastos, A.V.B. \& Achcar, R. (1994). "Dinâmica Profissional e Formação do Psicólogo: uma perspectiva de integração", In Conselho Federal de Psicologia, Psicólogo Brasileiro. Práticas emergentes e desafios para a formação, São Paulo: Casa do Psicólogo.

Bastos, A.V.B. (1988). "Áreas de Atuação - Em Questão o Nosso Modelo de Profissional", In Quem é o Psicólogo Brasileiro?, Conselho Federal de Psicologia.

Bicalho, M.L. (1996). "O Papel dos Conselhos Profissionais", Jornal do CRP-01, Brasília, Junho.

Carneiro, T.F. (1993). "Academia e Profíssão em Psicologia: da relação possível à relação desejável", Psicologia: Reflexão e Crítica, Porto Alegre, V.6, n.1/2, p.103-105.

Conselho Federal De Psicologia (1995). Psicologia - Legıslação, Brasília.

Costa Jr, A.L. \& Holanda, A.F. (1996). "Estágio em Psicologia: Discussão de Exigências e Critérios para o Exercicio de Supervisor de Estágio", Psicologia, Ciência e Profíssāo, Ano 16, No.2, pp.49.

Duran, A.P. (1994). "Alguns Dilemas na Formação do Psicólogo: Buscando sugestōes para superálos", In Conselho Federal de Psicólogo, Psicólogo Brasileiro. Práticas emergentes e desafios para a formação, São Paulo: Casa do Psicólogo.

Ferreira, A.B.H. (1994). Novo Dicionário da Língua Portuguesa, Rjo de Janeiro: Editora Martins Fontes.

Francisco, A.L. \& Bastos, A.V.B. (1992). "Conhecimento, Formação e Prática - o necessário caminho da integração", In Conselho Federal de Psicologia, Psicólogo Brasileiro. Construção de novos espaços, Campinas: Editora Átomo.

Mendonça Filho, J.B. (1993). "A Formação do Psicólogo", Anais da Semana de Psicologia, Belo Horizonte: Conselho Regional de Psicologia (4a Região).

Ministério do Trabalho (1994). Classificação Brasileira das Ocupaçōes, Brasília: SPES. 